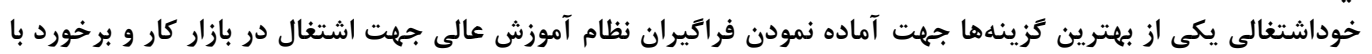

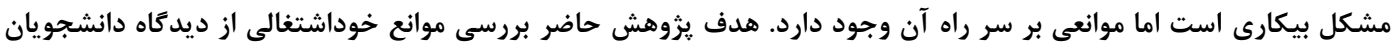

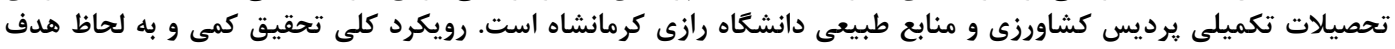

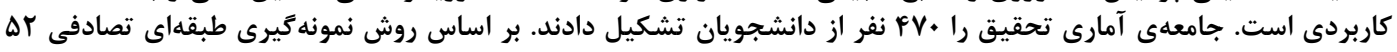

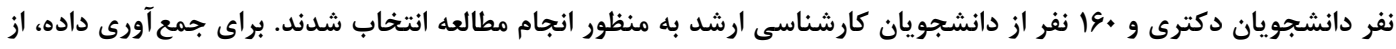

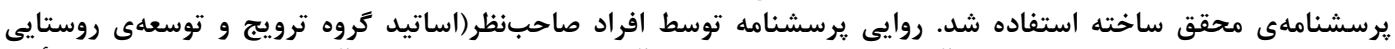

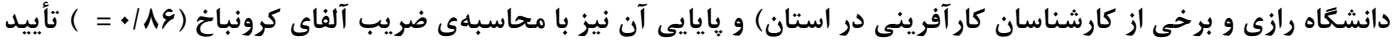

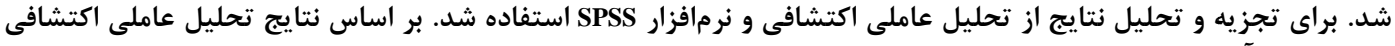

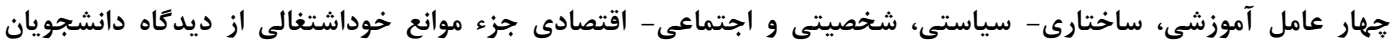

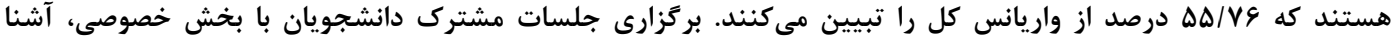

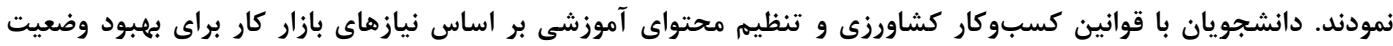
خوداشتغالى در آينده بِيشنهاد ميى قشودان

وازههاى كليدى: موانع خوداشتغالى، كار آفرينى، دانشجويان تحصيلات تكميلى، دانشكاه رازى

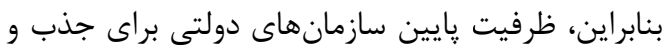

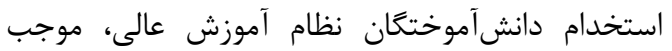

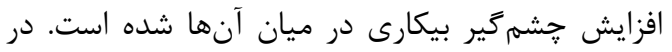

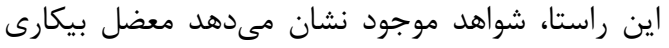

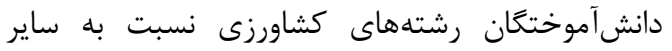

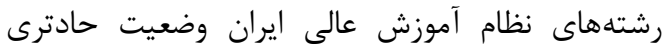

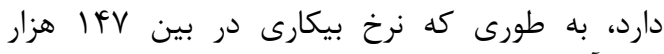

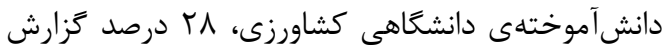

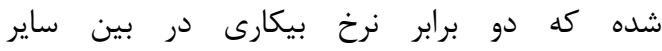

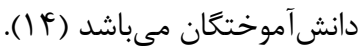

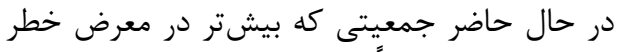

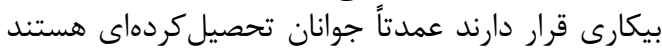

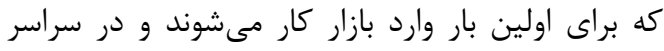

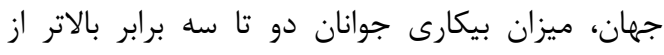

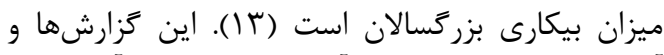

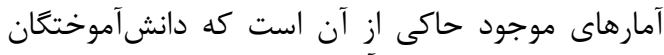

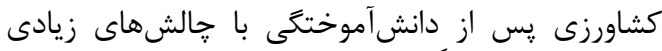

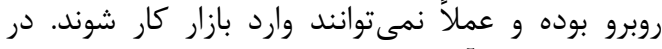

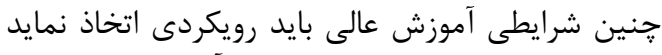

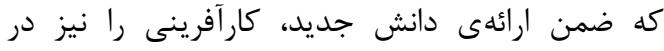

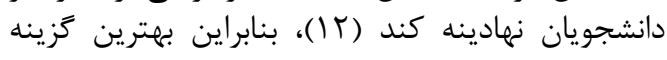

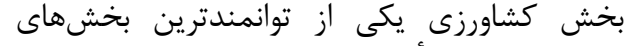

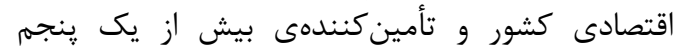

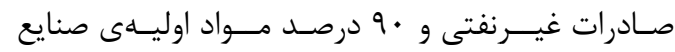

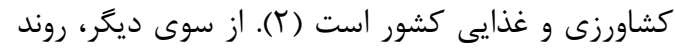

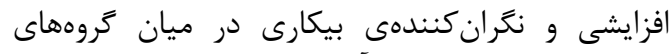

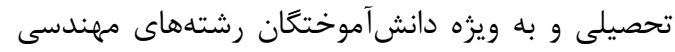

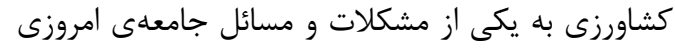

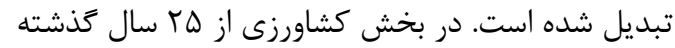

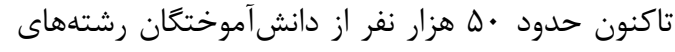

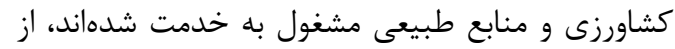

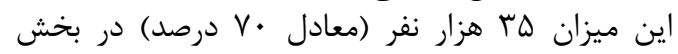

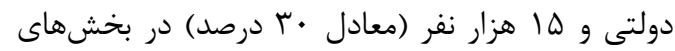

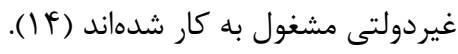

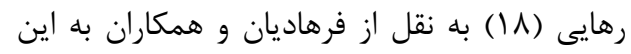

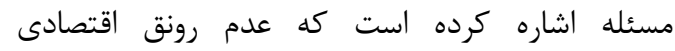

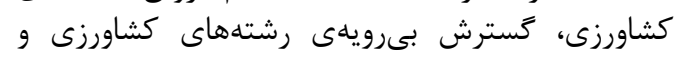

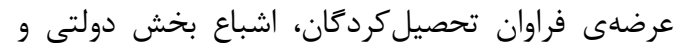

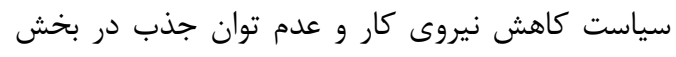

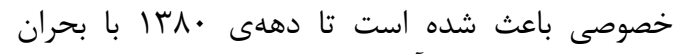
شديد بيكارى دانشآموختخان كشاورزى همراه باشئ داشد. 
طبق نظر برخى از محققان عدم تعامل بين

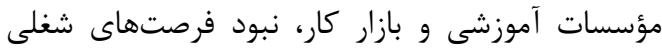

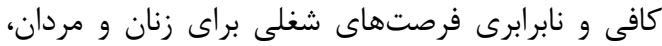

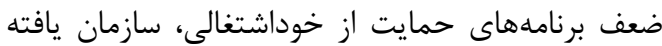

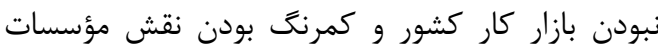

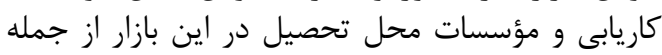

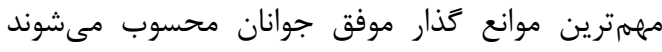

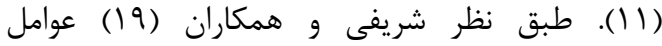

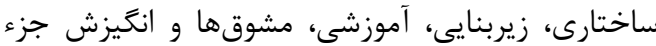

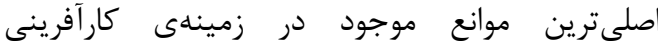
دانشجويان كشاورزى هستند. بر اساس ماس مطالعهى حلى حلاج

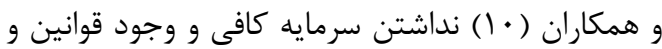

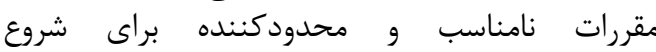
خوداشتغالى به ترتيب مههرترين موانع خوداشتغالى از

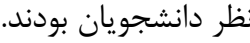
در مطالعهى حسينى و همكاران (Y) (I) نيز كمبود

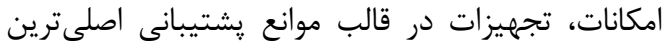

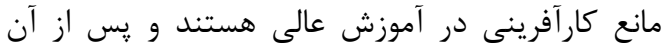

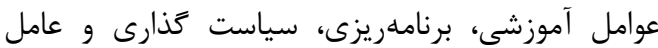

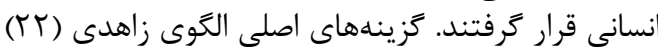

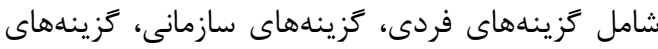

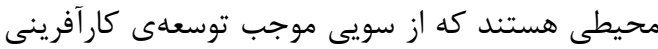

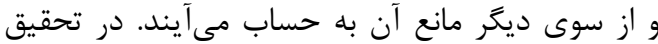

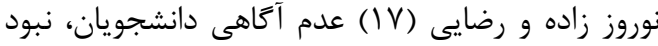

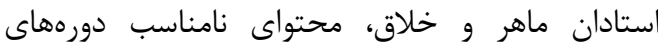

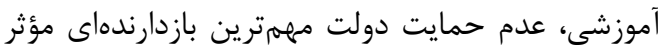

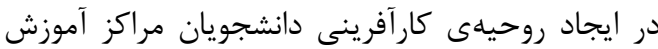

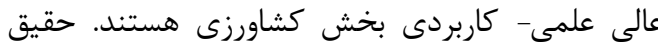

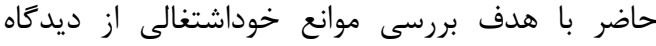

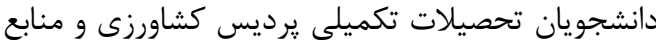

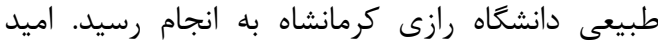

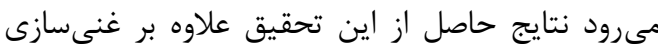

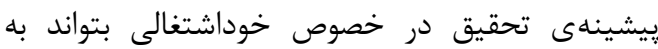
دستاندركاران آموزش عالى دئ در رابن رابطه با انجام رسالت

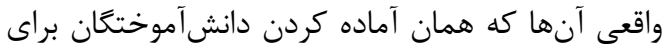
خوداشتغالى است، جامعه عمل بيوشاند.

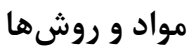

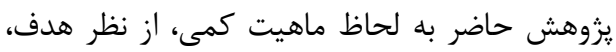

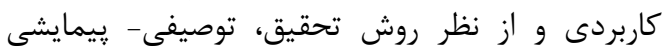

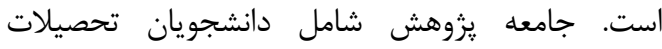

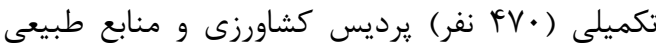

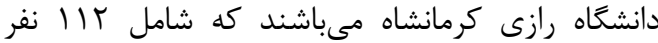

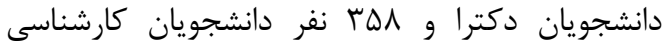

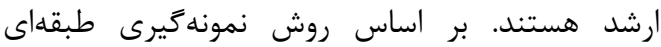
تصادفى با انتساب تناسب، هY هن نفر دانشجويان دكترى و

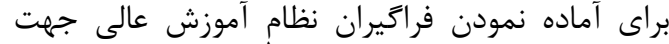

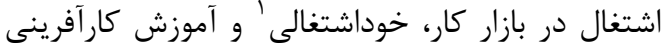

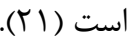
براى دست يابى به خوداشتغالى جوانان در آينده بايد

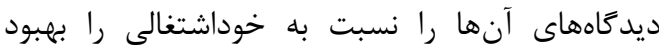

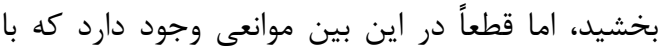

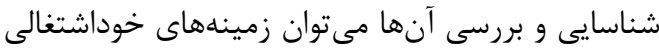

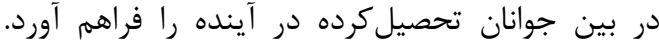

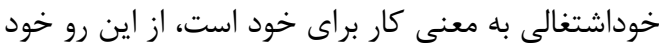

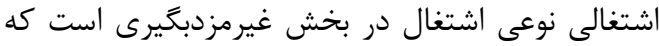

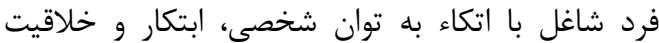

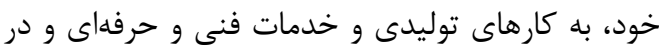

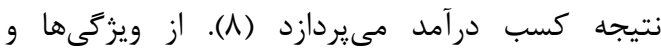

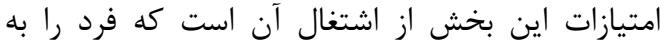

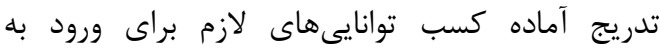

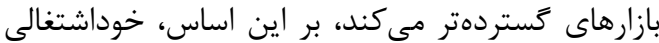

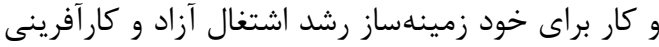

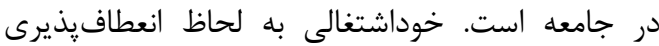

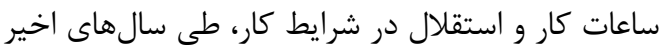

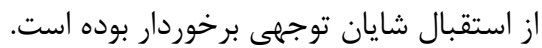

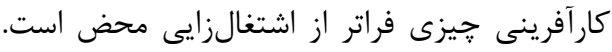

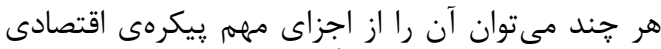

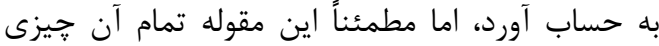

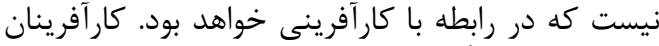

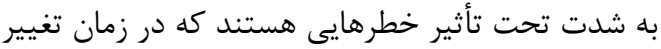

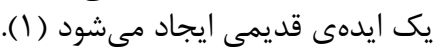

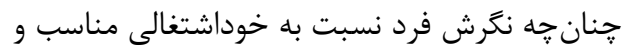

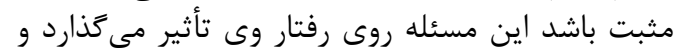

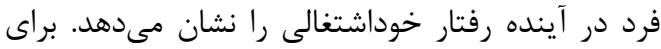

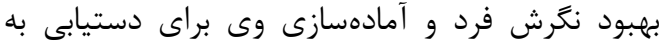

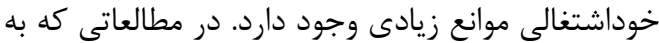

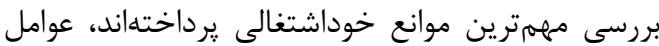

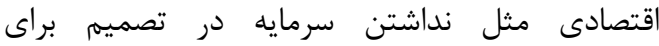

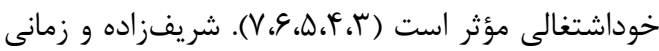

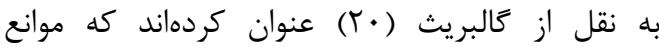

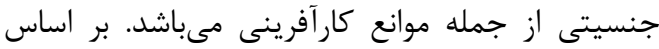

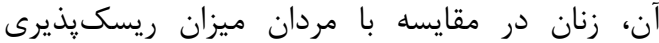

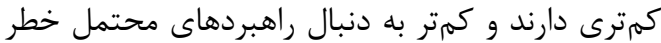

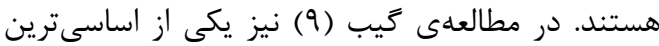

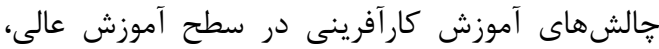
عدم حمايت سازمانى از آن آن توسط مؤسيسات آمرئ آموزش

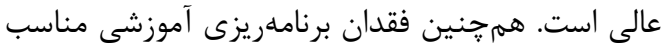

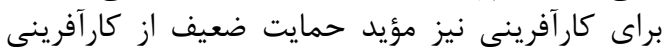

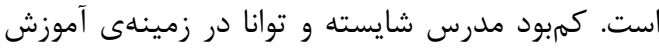

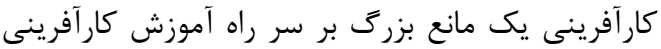

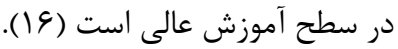


درصد) هستند. اكثريت دانشجويان مورد مطالعه بيكار

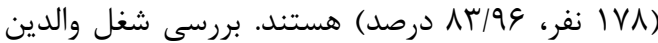

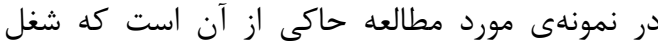

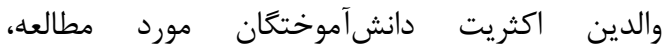

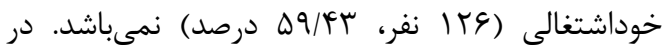

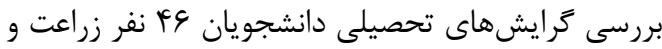

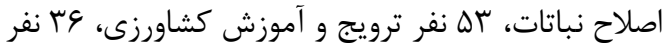

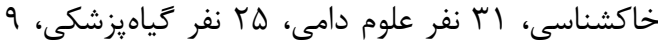

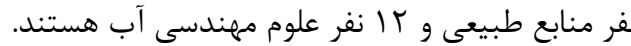
ولويتبندى موانع خوداشتغالى ولى نواني

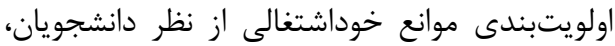

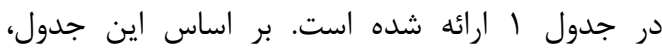

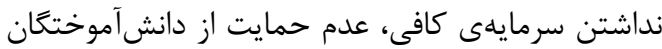

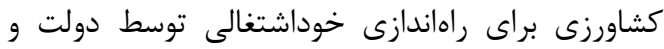

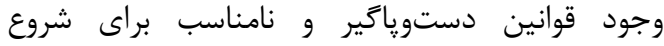

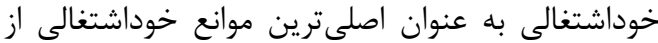
نظر دانشجويان هستند.
•19 نفر از دانشجويان كارشناسى ارشد به منظور انجام

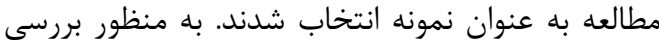

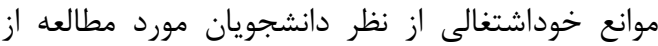

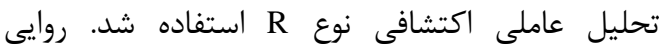

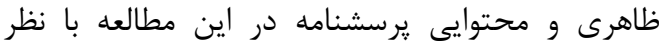

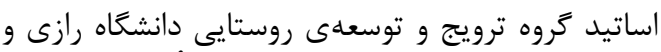

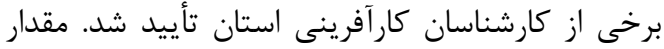

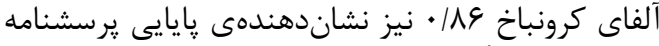

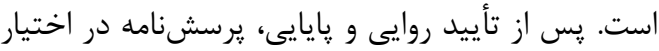

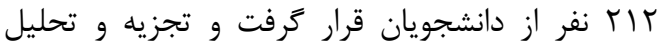
دادها توسط نرمافزار SPSS انجام كران كرفت

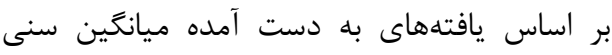

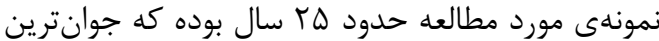

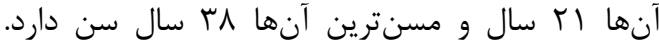

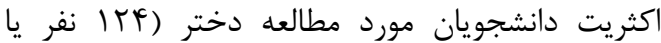

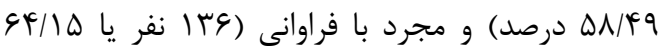

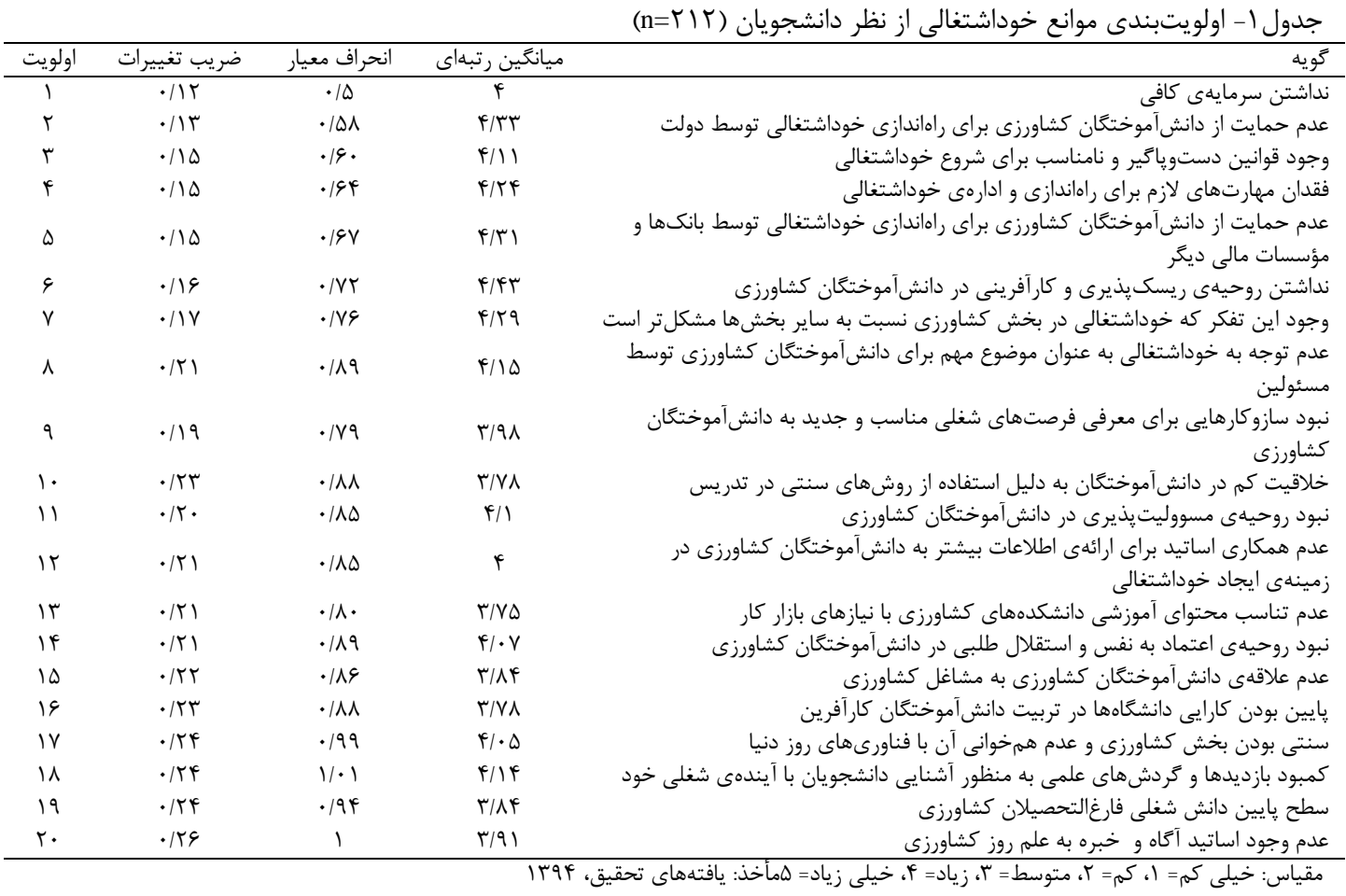

دادهها براى تحليل عاملى، آزمون بارتلت ' و و ضريب

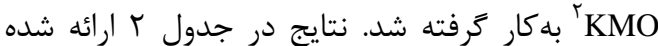

تحليل عاملى موانع خوداشتغالى

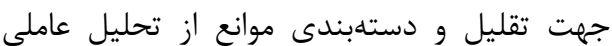
اكتشافى نوع R استفاده شد. براى تعيين مناسب است بودن 


\begin{tabular}{|c|c|}
\hline مقادير & آزمونها \\
\hline$\cdot /$ - VAV & مقدار KMO \\
\hline$r q \cdot \Delta / \Delta \& r$ & مقدار بارتلت \\
\hline$\cdot / \ldots$ & سطح معنى دارى \\
\hline
\end{tabular}

مأخذ: يافتههاى تحقيق،

مقدار واريانس مشترك بيشتر از مقدار واريانس خاص

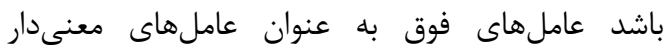

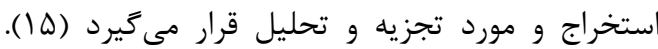

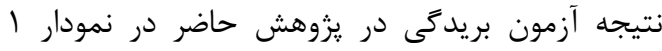
كزارش شده است
بر اساس نتايج جدول r r مشخص شد كه دادهها

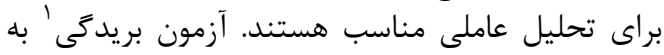

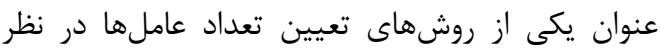

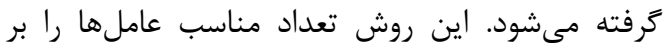

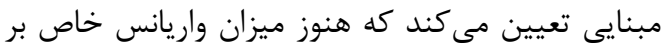
واريانس مشترك غلبه نكرده است، بنابراين، تا زمانى كه

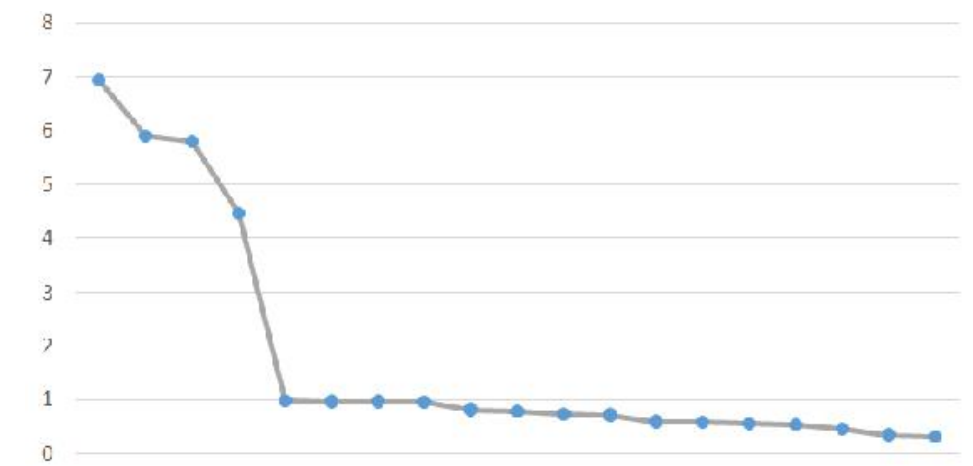

شكل اـ آزمون بريدگى مربوط به موانع خوداشتغالى از ديدكاه دانشجويان تحصيلات تكميلى.

طريق تحليل عاملى شناسايى شد. با توجه به مقدار

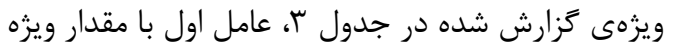

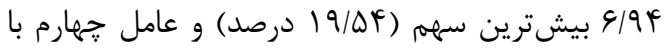

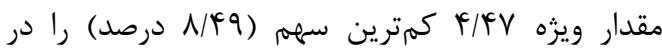
تبيين واريانس كل داشتند.
در اين تحقيق بر اساس نتايج حاصل از آزمون

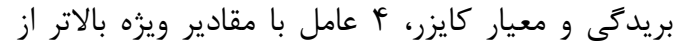

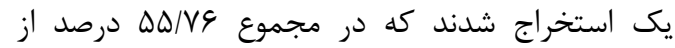

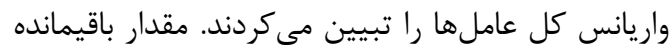

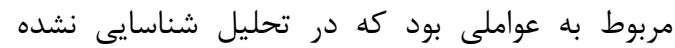
بودند، بنابراين، بيشتر از نيمى از موانع خوداشتغالى ازئ ندان

جدول זّ- تعداد عاملهاى استخراج شده و سهم هريك از آنها از تبيين واريانس

\begin{tabular}{|c|c|c|c|}
\hline درصد واريانس تجمعى & درصد واريانس مقدار ويزه & مقدار ويزه & شماره عامل \\
\hline $19 /\left.\Delta\right|^{F}$ & $19 / \Delta F$ & $9 / 94$ & 1 \\
\hline$r F / \cdot r$ & $\mid F / F \lambda$ & $\Delta / 91$ & r \\
\hline EV/Te & $I r / T \Delta$ & $\Delta / \Lambda)$ & r \\
\hline$\Delta \Delta / V \varphi$ & $1 / 49$ & $f / f V$ & f \\
\hline
\end{tabular}

هر عامل و بار عاملى آنها، عاملهاى مزبور به اين ترتيب نام كذارى شدند:

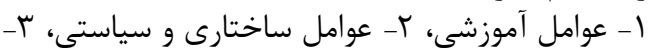

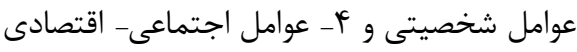

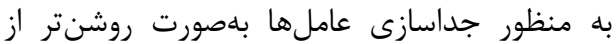
جرخش عاملى به روش واريماكس استفاده شده است راست

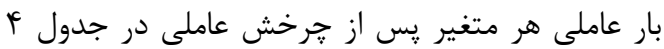

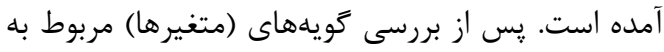




\begin{tabular}{|c|c|c|c|}
\hline بار عاملى & 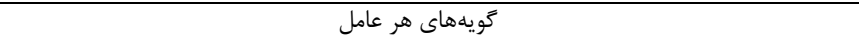 & عامل & رديف \\
\hline$\cdot /$ Mrt & يايين بودن كارايى دانشكاهها در تربيت دانشآموختكان كارآفرين & & \\
\hline$\cdot / V T V$ & خلاقيت كم در دانشآموختكان به دليل استفاده از روشهاى سنتى در تدريس & $y$ & \\
\hline$\cdot 1994$ & عدم همكارى اساتيد براى ارائهى اطلاعات بيشتر به دانشآموختكان كشاورزى در زمينهى ايجاد خوداشتغالى & $\overline{3}$ & 1 \\
\hline$\cdot 194 \Delta$ & عدم تناسب محتواى آموزشى دانشكدههاى كشاورزى با نيازهاى بازار كار & $\bar{g}$ & 1 \\
\hline$\cdot \mid \Delta \varphi$. & كمبود بازديدها و گردشهاى علمى به منظور آشنايى دانشجويان با آيندهى شغلى خود & 3 & \\
\hline$\cdot / \Delta \Delta F$ & سطح پايين دانش شغلى دانشآموختكان كشاورزى & & \\
\hline$\cdot / 490$ & عدم وجود اساتيد آكاه و خبره به علم روز كشاورزى & & \\
\hline$\cdot 1994$ & عدم حمايت از دانشآموختكان كشاورزى براى راهاندازى خوداشتغالى توسط دولت & $\frac{y}{8}$ & \\
\hline$\cdot \mid 9 \mathrm{H} \Lambda$ & وجود قوانين دستوياگير و نامناسب براى شروع خوداشتغالى & & \\
\hline$\cdot 1091$ & عدم حمايت از دانشآموختكان كشاورزى براى راهاندازى خوداشتغالى توسط بانكها و مؤسسات مالى ديكر & & r \\
\hline$\cdot 1094$ & نبود سازو كارهايى براى معرفى فرصتهاى شغلى مناسب و جديد به دانشآموختكان كشاورزى & & \\
\hline$\cdot / \Delta \wedge 9$ & سنتى بودن بخش كشاورزى و عدم همخوانى آن با فناورىهاى روز دنيا & & \\
\hline$\cdot|9 V|$ & نبود روحيهى اعتماد به نفس و استقلال طلبى در دانشآموختكان كشاورزى & $\frac{y}{9}$ & \\
\hline$\cdot|94|$ & عدم علاقهى دانشآموختكان كشاورزى به مشاغل كشاورزى ع ع & 3 & \\
\hline$\cdot 18 \mathrm{r} \cdot$ & نبود روحيهى مسووليتيذيرى در دانشآموختگان كشاورزى & $y^{3}$ & r \\
\hline$\cdot / \Delta \wedge \mathrm{V}$ & فقدان مهارتهاى لازم براى راهاندازى و ادارمى خوداشتغالى & : & \\
\hline$\cdot / \Delta V Y$ & 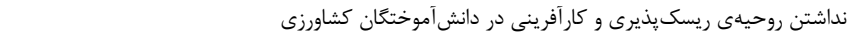 & $\mathrm{T}$ & \\
\hline$\cdot$ IFTD & وجود اين تفكر كه خوداشتغالى در بخش كشاورزى نسبت به ساير بخشها مشكل تر است & & \\
\hline$\cdot / \pi \Delta q$ & عدم توجه به خوداشتغالى به عنوان موضوع مهمم براى دانش آموختًان كشاورزى توسط مسئولين & $\begin{array}{l}3 \\
\overline{1} \\
\overline{4}\end{array}$ & $f$ \\
\hline$\cdot / \mathrm{TIV}$ & 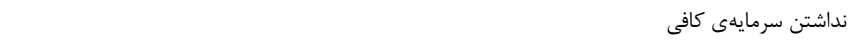 & $\frac{3}{y}$ & \\
\hline
\end{tabular}

مسووليتيذير نبودن و فقدان مهارتهاى لازم و ساير

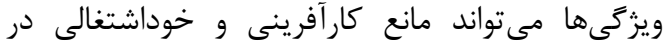

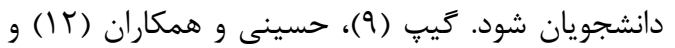

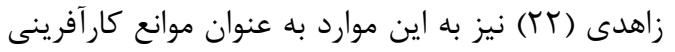

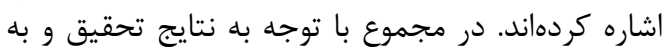

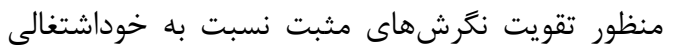

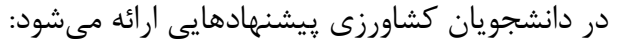

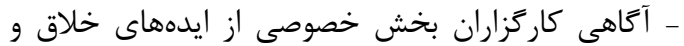

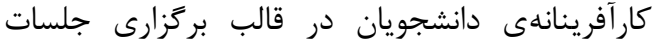

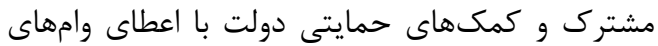

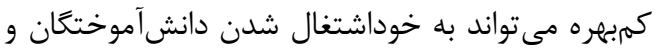

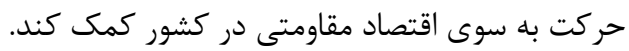

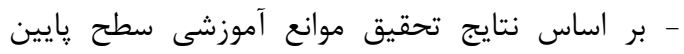

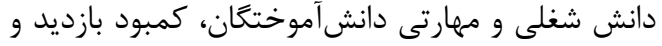

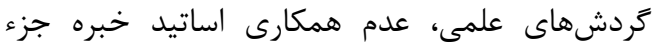

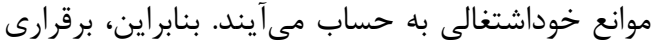

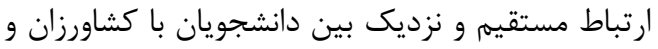

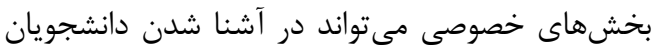

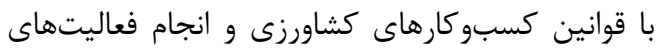
عملى در شرايط واقعى مؤثر واقع شودي.

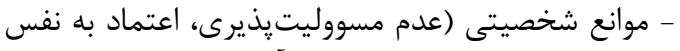

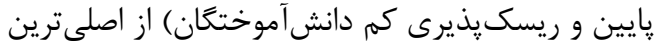

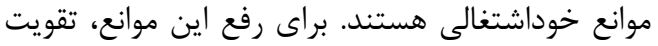

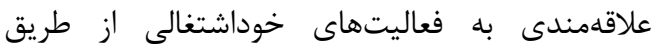

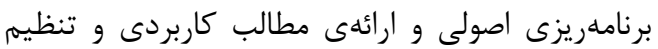

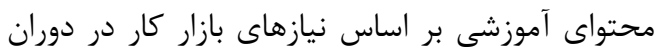

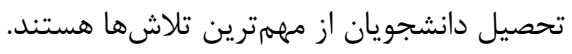

بر اساس نتايج تحقيق حاضر در مجموع موانع بر سر دان دان

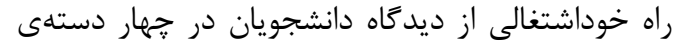

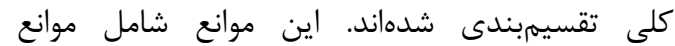

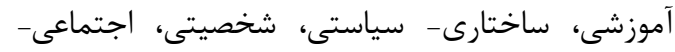

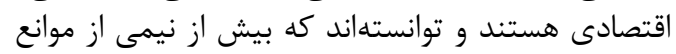

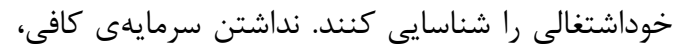

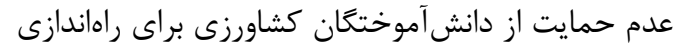

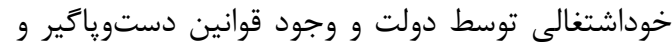

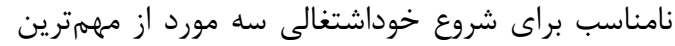

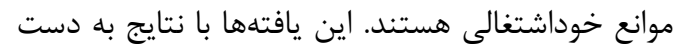

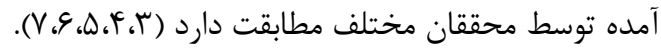

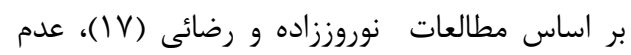

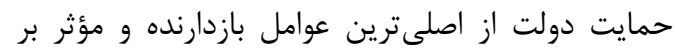

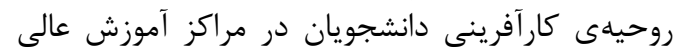

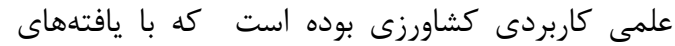

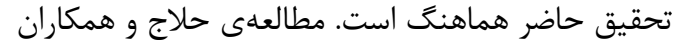

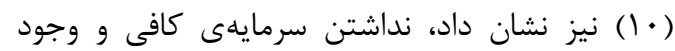

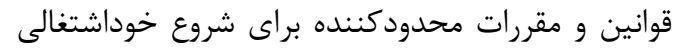
مهرمترين موانع از نظر دانشجويان بودين بوده است.

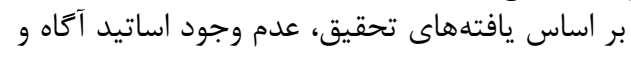

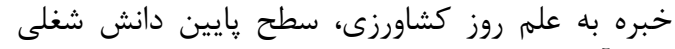

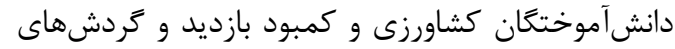

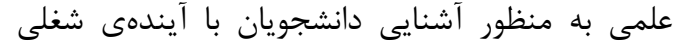

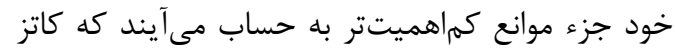

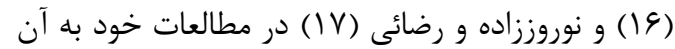

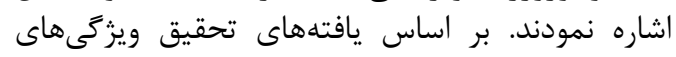

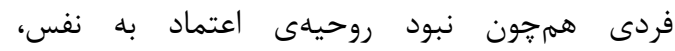


1. Miri, A.M. 2009. Entrepreneurship education the creation, development, orientations and challenges, Entrepreneurship Development, 1: 133-169 (In Persian).

2. Amir Teymori, S. and S. Khalilian. 2008. Growth of Productivity of Total Factors in the Agricultural Sector and Its Prospects in the Fourth Development Plan. Agricultural Economic and Development, 15: 37-52 (In Persian).

3. Baliamoune-Lutz, M., Z. Brixiova and L. Ndikumana. 2011. Credit Constraints and Productive Entrepreneurship in Africa, Political Economy Research Institute, Working paper series, 3: 134-161.

4. Botha, M. 2008. The Entrepreneur. In G. Nieman and C. Nieuwenhuizen (Eds). Entrepreneurship: a Sought African Perspective, Van Schaik publisher, Pretoria, South Africa: 29-51.

5. Cassar, G. 2004. The Financing of Business Start-Up. Journal of Business Venturing, 19: 261-283.

6. Ebben, J.J. 2008. Bootstrapping and the Financial Conditions of Small Firms. International Journal of Entrepreneurial Behavior and Research, 15: 346-363.

7. Ghambarali, R., H. Agahi, A.H.A. Baygi and K. Zarafshani. 2014. Assessing the Barriers to Access of Agricultural Entrepreneurs to Financial Capital. Journal of Entrepreneurship and Agriculture, 1: 37-51 (In Persian).

8. Ghavami, H. 2004. The study of self-employment compared of in wage employment. Journal of economic research, 63: 151-172 (In Persian).

9. Gibb, A. 2002. Creating Conductive Environments for Learning and Entrepreneurship, Industry and Higher Education, 16: 135- 148.

10. Hallaj, Z., A.R. Gheyasi and S. Esfarani. 2014. An Investigation of female students' attitude toward Self-Employment and that's Barriers (Case Study: Agriculture and Natural Resources Students, university of zabol). Fifth congress of agricultural extension and education sciences and natural resources of Iran, Zanjan University (In Persian).

11. Harandi, F. and Z. Fallah Mohsen Khani. 2007. Youth Employment and its Challenges. Social Welfare Quarterly, 25: 133-146 (In Persian).

12. Hosseini S.M., S.J. Hosseini and M.R. Soleimanpour. 2011. Identify and Analyze the Barriers to Entrepreneurship in Higher Education of Agriculture from the Views of Graduate Students. Iranian Journal of Agricultural Economics and Development, 41: 359-368 (In Persian).

13. International Lab our Organization (ILO). 2001. Youth and work: global Trend, International Labor Office, Geneva. Retrieved from: www.ilo.org/public/english.

14. Jalali, Kh. 2004. Organizing the Employment of Graduates in Field of Agriculture and Natural Resources. Journal of Agricultural Engineering and Natural Resources, 2: 19-23 (In Persian).

15. Kalantari, Kh. 2009. Data Processing and Analysis in Socio-Economic Research, Edition 4, Farhang Saba Publisher, Tehran, Iran: 388 pp (In Persian).

16. Katz, J.A. 2003. The Chronology and Intellectual Trajectory of American Entrepreneurship Education 1876. Journal of Business Venturing, 18: 283-300.

17. Noroz zadeh, R. and N. Rezaei. 2010. Encouragers and In hibit or Affecting on the Entrepreneurial Spirit from Students Perspective of Higher Education Centers of Agricultural Science-Practical Journal of Agricultural Education Administration Research, 12: 75- 90 (In Persian).

18. Rahaei, Z. 2005. Study of the Role of Higher Education in Solving the Problem of employment to fgraduates, Entrepreneurial University, the Needs of The Market, Monthly of Tadbir, 159, retrieved from: www.imi.ir/tadbir/tadbir-159/reports-159/2/asp (In Persian).

19. Sharifi, A., H.R. AliZadeh, A. Esmaeilipour and A. Soleimani. 2008. Factor Analysis of Barriers in the Field of Entrepreneurship of Agriculture Students from the Perspective of Senior Students of Agriculture(Case Study: College of Agriculture, Jiroft, Kerman Bahonar University Proceedings of the National Conference of Higher Education and Entrepreneurship (Past, Present, Future), the University of Human Sciences, Semnan University, 475- 484 (In Persian).

20. Sharifzadeh, M. and Gh.H. Zamani. 2006. Entrepreneurial Spirit in Agricultural Students: Case Study of Shiraz University. Iranian Journal of Agriculture Science, 37: 107-115 (In Persian).

21. Taj Abadi, R. 2008. Education and Development of entrepreneurship and Methods of Their application in Agricultural Higher Education System. National Conference on Entrepreneurship, Culture and Society, Islamic Azad University of Roodehen Branch, 1-78 (In Persian).

22.Zahedi, S.H. 2004. Systems Analysis of Options Affecting Entrepreneurship. Proceedings of Entrepreneurship and Advanced Technologies, Edition of Tehran University and the Institute of Research and Development Humanities, Tehran. First Edition: 230 pp (In Persian). 


\title{
Assessing the Self-Employment Barriers from the Perspective of Graduate Students of Campus of Agriculture and Natural Resources of Razi University, Kermanshah
}

\author{
Hossein Agahi ${ }^{1}$, Fatemeh Ghorbani Piralidehi ${ }^{2}$ and Samireh Sey Mohammadi ${ }^{3}$ \\ 1 and 3- Associate Professor and Ph.D. Student, Razi University, Kermanshah \\ 2- Ph.D. Student, Razi University, Kermanshah, \\ (Corresponding author: fateme_ghorbani1143@yahoo.com) \\ Received: January 11, $2016 \quad$ Accepted: April 11, 2016
}

\begin{abstract}
Self-employment is one of the best options to prepare higher education system learners for employment in the labor market and resolving the unemployment problem but there are barriers against it. The purpose of this study is to assess the self-employment barriers from the perspective of graduate students of Campus of Agriculture and Natural Resources of Razi University in Kermanshah. The general approach of research is quantitative and in terms of target is practical. Statistical population consisted of 470 students. Based on random stratified sampling method 52 Ph.D. students and 160 M.Sc. students were selected in order to do this study. Was used data collection, the researcher made questionnaire. The validity of questionnaire was confirmed by a panel of experts (scientific board members of department of extension and rural development of Razi University and some of entrepreneurship experts in province) and its reliability was calculated using alpha Cronbach coefficient $(\alpha=0.86)$. The exploratory factor analysis and SPSS software was used to analyze the results. Based on the results of exploratory factor analysis, 4 factors include of training, structural- political, personality and social- economical are the barriers to self-employment from the perspective of students who explained55.76 percent of the total variance. Holding of joint meetings of students with the private sector, become familiar students with the rules of agricultural businesses and setting up educational content based on labor market needs to improve the self-employed status in the future is recommended.
\end{abstract}

Keywords: Entrepreneurship, Graduate Students, Razi University, Self-Employment Barriers 